\title{
Crystallization and lamellar nanosheet formation of an aromatic dipeptoid
}

Article

Accepted Version

Castelletto, V., Chippindale, A. M., Hamley, I. W., Barnett, S., Hasan, A. and Lau, K. H. A. (2019) Crystallization and lamellar nanosheet formation of an aromatic dipeptoid. Chemical Communications, 55. pp. 5867-5869. ISSN 1359-7345 doi: https://doi.org/10.1039/C9CC02335F Available at https://centaur.reading.ac.uk/83535/

It is advisable to refer to the publisher's version if you intend to cite from the work. See Guidance on citing.

To link to this article DOI: http://dx.doi.org/10.1039/C9CC02335F

Publisher: Royal Society of Chemistry

All outputs in CentAUR are protected by Intellectual Property Rights law, including copyright law. Copyright and IPR is retained by the creators or other copyright holders. Terms and conditions for use of this material are defined in the End User Agreement.

\section{www.reading.ac.uk/centaur}

\section{CentAUR}

Central Archive at the University of Reading 
Reading's research outputs online 


\section{Crystallization and Lamellar Nanosheet Formation of an Aromatic Dipeptoid}

Received 00th January 20xx, Accepted 00th January 20xx DOI: $10.1039 / x 0 x \times 00000 x$

\author{
Valeria Castelletto, ${ }^{a}$ Ann M. Chippindale, ${ }^{a}$ Ian W. Hamley, ${ }^{a, *}$ Sarah Barnett, ${ }^{b}$ Abshar Hasan ${ }^{c}$ and \\ King Hang Aaron Lau ${ }^{c}$
}

\begin{abstract}
An aromatic peptoid analogue of the diphenylalanine dipeptide self-assembles in aqueous solution and the first crystal structure was obtained for this class of compound. This reveals molecular packing stabilized by networks of hydrogen bonds. Freefloating nanosheet lamellar structures are observed in solution, which form via cooperative intermolecular interactions driven by $\pi$ - stacking
\end{abstract}

The Peptoids are intriguing biomimetic molecules which have unique properties compared to peptides, to which they are related as $\mathrm{N}$-functionalized instead of $\alpha \mathrm{C}$-functionalized analogues. ${ }^{1,2}$ Peptoids are in fact $\mathrm{N}$-glycine derivatives and specific sequences can confer bioactivity and self-assembly behavior. They have attracted interest since they have a range of properties including enhanced biological stability (reduced hydrolysis), and the potential to evade the immune system. ${ }^{3,4}$ In addition, antifouling properties have been reported, ${ }^{5-7}$ and they have great potential in drug discovery (due to their affinity for proteins, and the ability to prepare libraries of peptoids by automated synthesis methods), ${ }^{8,9}$ among others.

The discovery that diphenylalanine (FF) can self-assemble into nanotubes in aqueous solution ${ }^{10}$ has stimulated great interest due to the remarkable range of properties displayed by this material, especially (opto)electronic, ${ }^{11,12}$ with great potential in nanotechnology development. ${ }^{13}, 14$ This inspired us to investigate the self-assembly and structural properties of peptoid analogues of FF.

\footnotetext{
a. Department of Chemistry, University of Reading, Whiteknights, Reading RG6 6AD, UK

b. Diamond Light Source, Harwell Science and Innovation Campus, Didcot, OX11 $O D E, U K$

c. c WestCHEM/Department of Pure \& Applied Chemistry, University of Strathclyde, 295 Cathedral Street, Glasgow, UK

Electronic Supplementary Information (ESI) available: Experimental methods, LCMS, ESI-MS and HPLC data, table of crystallization conditions, table of SAXS fitting parameters addi-tional POM and TEM images, original fluorescence spectra. The single crystal XRD data is deposited as CCDC 1904300. For ESI and crystallographic data in CIF format see DOI: 10.1039/x0xx00000x
}

There are only a handful crystal structures of oligo-peptoids and these are mainly for cyclic peptoids, ${ }^{15-17}$ and to the best of our knowledge there is only one prior published crystal structure of a linear oligomeric peptoid, pentameric $\mathrm{N}$-(1cyclohexylethyl)glycine. ${ }^{18}$ In this manuscript, we report on the crystallization behavior of a dipeptoid containing two residues with an aromatic sidechain, Nbn [ $N$-benzylglycine] (Fig.1a), which is an analogue of the amino acid phenylalanine (F). We observed that peptoid NbnNbn is generally unstable and undergoes cyclisation over a period of time to form di-ketopiperazine (the crystal structure of which we obtained, this having also been reported previously ${ }^{19}$ ). To overcome this, we capped the $\mathrm{N}$ terminal by acetic anhydride reaction on resin, producing a peptoid referred to in the following as CapNFF. Synthesis details are provided in the SI along with LC-MS (SI Fig.S1), ESI-MS (SI Fig.S2) and HPLC data (SI Fig.S3) which confirm the expected product, obtained with high purity (the purity is also confirmed since we were able to crystallize the sample and obtain a single crystal structure as described below).
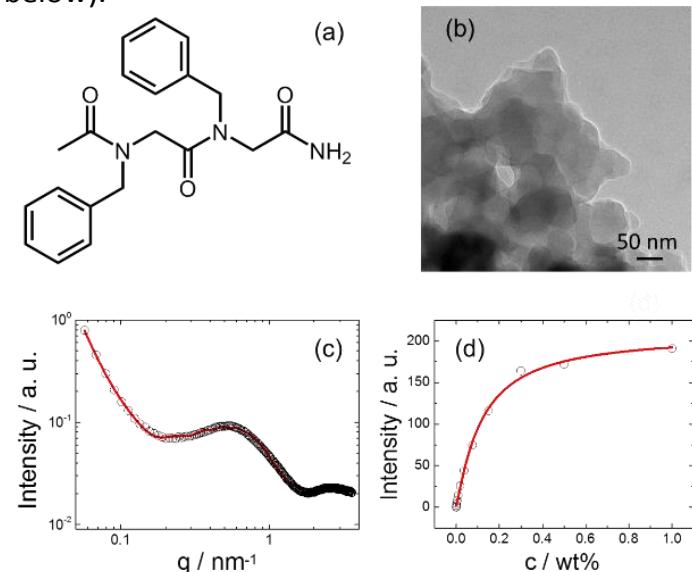

Fig.1. (a) Molecular structure of CapNFF, (b) TEM image of $2 \mathrm{wt} \%$ sample in $70 \%$ acetonitrile: $30 \%$ water, (c) SAXS intensity profile (measured - open circles, every $5^{\text {th }}$ point plotted for visibility) with form factor fit (red line) for a $2 \mathrm{wt} \%$ sample in
$70 \%$ acetonitrile: $30 \%$ water, (d) Concentration-dependent $\mathrm{Nbn}$ fluorescence $70 \%$ acetonitrile: $30 \%$ water, (d) Concentration-dependent $\mathrm{Nbn}$ fluorescence
intensity with fit to Hill equation, showing cooperative molecular interactions. 
We first investigated the self-assembly of capNFF in solution (mixed water and acetonitrile due to insolubility in water). Fig.1b and SI Fig.S4 show transmission electron microscope (TEM) images which reveal free-floating nanosheet structures. This was further probed by small-angle X-ray scattering (SAXS) and the measured SAXS intensity profile is shown in Fig.1c along with a model form factor fit based on a form factor developed for lamellar structures ${ }^{20}$ and used by our group to describe peptide $^{21}$ and lipopeptide 22 nanosheets. The form factor describes the data very well apart from the broad Bragg peak at $\mathrm{q}=2.6 \mathrm{~nm}^{-1}$ which corresponds to $d=2.4 \mathrm{~nm}(24 \AA$ $)$, which is very close to the $a$ cell parameter from the crystal structure (Table 1 ) and suggests possible internal packing of the molecules within the free-floating nanosheets, although the peak is not sharp and this ordering is not crystalline. The fitted parameters include the nanosheet thickness $t=(6.9 \pm 1.5) \mathrm{nm}$ (a full list of fit parameters is listed in Table S2). This thickness indicates that the nanosheets comprise approximately 5-10 layers of CapNFF molecules, based on the estimated molecular length. The nanosheet structure is thus confirmed by both TEM and SAXS. The nanosheet structure formed by CapNFF may be compared with the free-floating nanosheet (individual lamellae) observed for mixtures of oppositely charged alternating NceNpe and Nae-Nphe [Npe: N- (2-phenylethyl)glycine, Nce: $\mathrm{N}$-(2carboxyethyl glycine), Nae: $N$-(2-aminoethyl) glycine] oligopeptoids. ${ }^{23}$ We examined the self-assembly process of CapNFF using fluorescence spectroscopy, measuring the concentration dependence of the peak associated with Npe aromatic $\pi-\pi$ stacking interactions. Fig.1d shows the fluorescence intensity increase with concentration along with a fitted sigmoidal curve using the Hill equation, the Hill coefficient was found to be $n=1.15$. These results indicate positive cooperative binding associated with intermolecular interactions driven by $\pi-\pi$ stacking. The original fluorescence spectra are shown in SI Fig.S5.

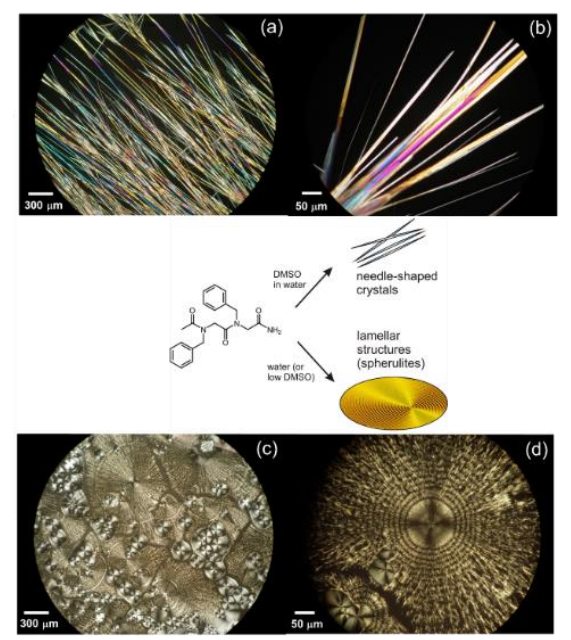

Fig.2. (a-d) Polarized optical microscopy images of samples (referring to SI Table 1) shown schematically in the center.

A number of methods have been developed to crystallize proteins and peptides including batch crystallization, liquidliquid diffusion, vapor diffusion (including hanging and standing drop techniques). ${ }^{24-26}$ These all effect supersaturation, which is a pre-requisite for crystal formation. These methods may be useful in the crystallization of peptoids, however we developed a new simpler method based on dispersion in a low volatility solvent DMSO, followed by injection in water and subsequent evaporation of the mixture in a closed box. A list of crystallization methods tested is listed in SI Table 1. Method A led to the development of well-defined needle-shaped crystals (Fig.2a,b). In contrast, absence of DMSO or an excess of water relative to DMSO led to the formation of spherulite structures (Fig.2c,d, SI Fig.S6). The formation of spherulites is well known during polymer crystallization as the crystal lamellae grow radially. ${ }^{27-29}$ Maltese cross structures are observed under the polarizing optical microscope for such structures based on radial growth of planar lamellae, however if twisting of the lamellae occurs as growth progresses radially, banded spherulites are observed by polarized optical microscopy (POM). ${ }^{27-29}$ Fig.2c,d show examples of both structures in samples of CapNFF which did not crystallize or which did not fully crystallize. These spherulite structures are consistent with the formation of 2D lamellar structures growing on planar surfaces. Our findings show that careful control of the nonvolatile solvent content and mixture volatility are essential to produce peptoid crystals, and that lamellar structures can also be prepared by drying from suitable mixed solvents. Table 1. Crystallographic Data for CapNFF

\begin{tabular}{|c|c|}
\hline Chemical formula & $\mathrm{C}_{20} \mathrm{H}_{23} \mathrm{~N}_{3} \mathrm{O}_{3}$ \\
\hline$M r$ & 353.41 \\
\hline Crystal system & orthorhombic \\
\hline Space group & $\mathrm{Pna2}_{1}$ (no. 33) \\
\hline Z & 4 \\
\hline$a / \AA ̊$ & $23.73549(11)$ \\
\hline$b / \AA$ & $16.75238(8)$ \\
\hline$c / \AA ̊$ & $4.78477(2)$ \\
\hline$V / \AA^{3}$ & $1902.549(15)$ \\
\hline$\rho_{\text {calc }} / \mathrm{g} \mathrm{cm}^{-1}$ & 1.234 \\
\hline Crystal habit & Colourless needle \\
\hline Crystal dimensions /mm & $0.13 \times 0.015 \times 0.010$ \\
\hline Radiation type & Synchrotron, $\lambda=0.6889 \AA$ \\
\hline$T / K$ & 100 \\
\hline$\mu / \mathrm{mm}^{-1}$ & 0.078 \\
\hline No reflections measured & 41114 \\
\hline No independent reflections & 9215 \\
\hline $\mathrm{R}_{\text {int }}$ & 0.0411 \\
\hline No reflections $(I>2 \sigma(I))$ & 7635 \\
\hline No parameters, restraints & 327,1 \\
\hline Flack parameter & $0.2(4)$ \\
\hline $\mathrm{H}$-atom treatment & $x, y, z$ and Uiso refined \\
\hline$R\left(\mathrm{~F}^{2}\right), R_{\mathrm{w}}\left(\mathrm{F}^{2}\right)$ for observed data & $0.0384,0.0942$ \\
\hline CCDC Code & 1904300 \\
\hline
\end{tabular}

The needle-shaped crystals of CapNFF obtained were sufficiently large to enable synchrotron $\mathrm{X}$-ray single crystal structure determination. The peptoid crystallizes in an orthorhombic $P n a 2_{1}$ structure, with unit cell parameters listed 
in Table 1. The crystal structure (Fig. 3) reveals the presence of hydrogen bonds between the $\mathrm{N}$ terminal nitrogen (N22) and the $\mathrm{N}$-terminal carboxyl O (O21) and the $\mathrm{C}$ terminal O (O25) (Fig.3b) (the atom numbering scheme is shown in SI Fig.7). Remarkably, the $\mathrm{N}(22) \ldots \mathrm{O}(21)$ hydrogen bonds network extends along the $c$ axis (Fig.3c) while there is a network of $\mathrm{N}(22) . . \mathrm{O}(25)$ hydrogen bonds in the (a,c) plane (Fig.3d). The hydrogen bond geometry is detailed in SI Table 3. It is also interesting to note that different residues along CapNFF adopt different backbone twists in the crystalized structure, exhibiting both cis and trans conformations, as may be expected of an achiral short and flexible backbone. ${ }^{30}$ In contrast, recent studies of longer peptoids have shown that the cis conformation is preferred, especially as chain length increases for self-assembly or crystallizing sequences. ${ }^{31}$ (a)

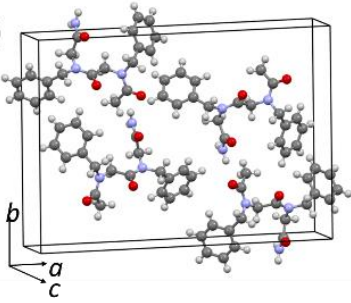

(c)

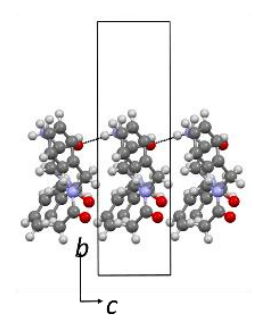

(b)

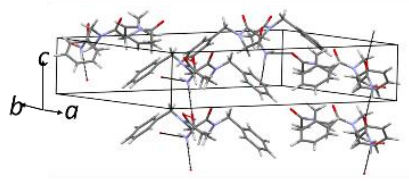

(d)

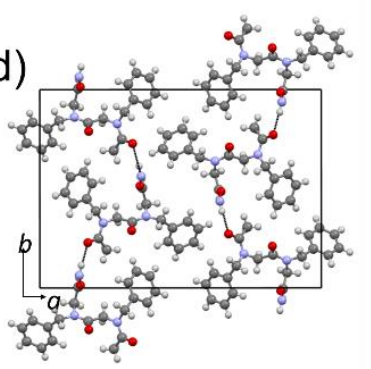

Fig.3. Crystal structure from single crystal XRD. (a) Showing unit cell, (b) Showing network of $\mathrm{H}$-bonds, (c) Chains of $\mathrm{H}$-bonds in the $(\mathbf{b}, \mathbf{c})$ plane, (d) $\mathrm{H}$-bonds in the (a,b) plane.

In summary, we show that the dipeptoid CapNFF forms either needle-shaped crystals or lamellar spherulitic assemblies and it undergoes self-assembly in aqueous solution to form freefloating nanosheets. The self-assembly is driven by cooperative interactions between the NBN aromatic units. The first crystal structure for a dipeptoid reveals an orthorhombic structure in which the (significantly twisted) molecules are packed with $\mathrm{H}$ bond arrays running along $b$ and $c$ axes. By varying solvent volatility, it is also possible to prepare lamellar structures consistent with spherulite formation. The novel crystallization method employed to produce the CapNFF peptoid crystals is also expected to find broader use in crystallizing other small peptoids, and potentially peptides. This is currently under investigation. CapNFF is likely to attract considerable interest as a peptoid analogue of $\mathrm{FF}$, which has generated immense attention as a minimal peptide building motif for various functional nanostructures possessing unique mechanical properties (high modulus) and a range of applications from biomaterials to energy materials. ${ }^{10,13,14,32}$
Our results show that self-assembly does occur in the peptoid in a mixed aqueous solution, and it is driven by $\pi-\pi$ stacking, as in FF but without the peptide amide $\mathrm{H}$-bond stabilization. This leads to a different mode of self-assembly - nanosheets in the CapNFF peptoid rather than nanotubes in FF.

We thank EPSRC for the award of a Platform Grant to IWH (EP/L020599/1). We thank Diamond for the award of beamtime for single crystal X-ray diffraction (ref. CY22932-1) and SAXS (ref. SM18523-1). AH thanks the Commonwealth Scholarship Commission for a Split Site award (INCN-2017-50). The work of KHAL was supported by a young investigator grant from the Human Frontier Science Program (RGY0074/2016).

\section{Conflicts of interest}

There are no conflicts to declare.

\section{Notes and references}

1. J. Sun and R. N. Zuckermann, ACS Nano, 2013, 7, 47154732.

2. K. H. A. Lau, Biomater. Sci., 2004, 2, 627-633.

3. A. S. Knight, E. Y. Zhou, M. B. Francis and R. N. Zuckermann, Adv. Mater., 2015, 27, 5665-5691.

4. S. M. Miller, R. J. Simon, S. Ng, R. N. Zuckermann, J. M. Kerr and W. H. Moos, Drug Dev. Res., 1995, 35, 20-32.

5. A. R. Statz, J. P. Park, N. P. Chongsiriwatana, A. E. Barron and P. B. Messersmith, Biofouling, 2008, 24, 439-448.

6. K. H. A. Lau, C. L. Ren, T. S. Sileika, S. H. Park, I. Szleifer and P. B. Messersmith, Langmuir, 2012, 28, 16099-16107.

7. C. Leng, H. G. Buss, R. A. Segalman and Z. Chen, Langmuir, 2015, 31, 9306-9311.

8. R. J. Simon, R. S. Kania, R. N. Zuckermann, V. D. Huebner, D. A. Jewell, S. Banville, S. Ng, L. Wang, S. Rosenberg, C. K. Marlowe, D. C. Spellmeyer, R. Y. Tan, A. D. Frankel, D. V. Santi, F. E. Cohen and P. A. Bartlett, Proc. Nat. Acad. Sci USA, 1992, 89, 9367-9371.

9. R. N. Zuckermann and T. Kodadek, Curr. Opin. Mol. Ther., 2009, 11, 299-307.

10. M. Reches and E. Gazit, Science, 2003, 300, 625-627.

11. L. Adler-Abramovich and E. Gazit, Chem. Soc. Rev., 2014, 43, 6881-6893.

12. K. Tao, P. Makam, R. Aizen and E. Gazit, Science, 2017, 358, 7.

13. E. Gazit, Chem. Soc. Rev., 2007, 36, 1263-1269.

14. N. Kol, L. Adler-Abramovich, D. Barlam, R. Z. Shneck, E. Gazit and I. Rousso, Nano Lett., 2005, 5, 1343-1346.

15. E. De Santis, T. Hjelmgaard, S. Faure, O. Roy, C. Didierjean, B. D. Alexander, G. Siligardi, R. Hussain, T. Javorfi, A. A. Edwards and C. Taillefumier, Amino Acids, 2011, 41, 663672.

16. A. Meli, E. Macedi, F. De Riccardis, V. J. Smith, L. J. Barbour, I. Izzo and C. Tedesco, Angew. Chem. Int. Ed. Engl., 2016, 55, 4679-4682.

17. C. Tedesco, R. Schettini, V. Iuliano, G. Pierri, A. N. Fitch, F. De Riccardis and I. Izzo, Cryst. Growth Des., 2019, 19, 125133. 
18. C. W. Wu, K. Kirshenbaum, T. J. Sanborn, J. A. Patch, K. Huang, K. A. Dill, R. N. Zuckermann and A. E. Barron, J. Am. Chem. Soc., 2003, 125, 13525-13530.

19. E. J. Robertson, C. Proulx, J. K. Su, R. L. Garcia, S. Yoo, E. M. Nehls, M. D. Connolly, L. Taravati and R. N. Zuckermann, Langmuir, 2016, 32, 11946-11957.

20. G. Pabst, M. Rappolt, H. Amenitsch and P. Laggner, Phys. Rev. E, 2000, 62, 4000-4009.

21. I. W. Hamley, A. Dehsorkhi and V. Castelletto, Chem. Comm., 2013, 49, 1850-1852.

22. V. Castelletto, R. J. Gouveia, C. J. Connon and I. W. Hamley Faraday Discussions, 2013, 166, 381-397.

23. K. T. Nam, S. A. Shelby, P. H. Choi, A. B. Marciel, R. Chen, L. Tan, T. K. Chu, R. A. Mesch, B. C. Lee, M. D. Connolly, C. Kisielowski and R. N. Zuckermann, Nature Mater., 2010, 9, 454-460.

24. D. E. McRee, Practical Protein Crystallography, Academic Press, San Diego, 1993.

25. J. Drenth, Principles of Protein X-ray Crystallography, Springer, New York, 2010.

26. A. McPherson and J. A. Gavira, Acta Crystallogr. F-Struct. Biol. Commun., 2014, 70, 2-20.

27. H. D. Keith and F. J. Padden, Macromolecules, 1996, 29, 7776-7786.

28. U. W. Gedde, Polymer Physics, Chapman and Hall, London, 1995.

29. J. Albuerne, L. Márquez, A. J. Müller, J. M. Raquez, P. Degée., P. Dubois, V. Castelletto and I. W. Hamley, Macromolecules, 2003, 36, 1633-1644.

30. B. C. Hudson, A. Battigelli, M. D. Connolly, J. Edison, R. K. Spencer, S. Whitelam, R. N. Zuckermann and A. K. Paravastu, J. Phys. Chem. Lett., 2018, 9, 2574-2578.

31. D. R. Greer, M. A. Stolberg, J. Kundu, R. K. Spencer, T. Pascal, D. Prendergast, N. P. Balsara and R. N.

Zuckermann, J. Am. Chem. Soc., 2018, 140, 827-833.

32. J. H. Lee, K. Heo, K. Schulz-Schonbagen, J. H. Lee, M. S. Desai, H. E. Jin and S. W. Lee, ACS Nano, 2018, 12, 81388144. 